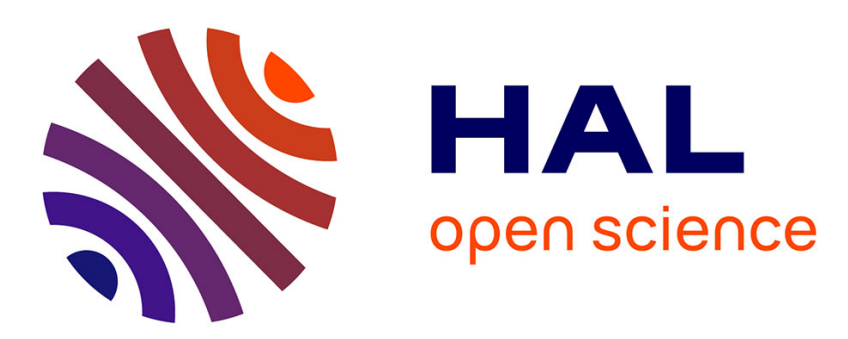

\title{
Educational planning: a simulation approach for the creation or closure of school classes
}

Marie-Benoît Magrini, Florent Bonneu, Christine Thomas-Agnan, Sandrine Coelho

\section{- To cite this version:}

Marie-Benoît Magrini, Florent Bonneu, Christine Thomas-Agnan, Sandrine Coelho. Educational planning: a simulation approach for the creation or closure of school classes. Environment and Planning B: Planning and Design, 2011, 38 (4), pp.595-615. 10.1068/b36043 . hal-02650900

\section{HAL Id: hal-02650900 https://hal.inrae.fr/hal-02650900}

Submitted on 29 May 2020

HAL is a multi-disciplinary open access archive for the deposit and dissemination of scientific research documents, whether they are published or not. The documents may come from teaching and research institutions in France or abroad, or from public or private research centers.
L'archive ouverte pluridisciplinaire HAL, est destinée au dépôt et à la diffusion de documents scientifiques de niveau recherche, publiés ou non, émanant des établissements d'enseignement et de recherche français ou étrangers, des laboratoires publics ou privés. 


\title{
Educational planning: a simulation approach for the creation or closure of school classes
}

\section{Marie-Benoît Magrini}

French National Institute for Agricultural Research (INRA) of Toulouse, UMR1248 AGIR, BP 52627, 31326 Castanet-Tolosan Cedex, France; e-mail: mbmagrini@toulouse.inra.fr

\section{Florent Bonneu}

Université d'Avignon et des Pays de Vaucluse, Laboratoire de Mathématiques d'Avignon (EA 2151), 84018 Avignon, France; e-mail: florent.bonneu@univ-avignon.fr

\section{Christine Thomas-Agnan}

Toulouse School of Economics, Manufacture des Tabacs, 21 Allées de Brienne, 31000 Toulouse, France; e-mail: cthomas@cict.fr

\section{Sandrine Coelho}

BVA, 75 rue Saint-Jean, BP 53110, 31131 Balma cedex, France; e-mail: sandrine.coelho@bva.fr Received 3 April 2009; in revised form 18 October 2010

\begin{abstract}
In this paper we deal with the problem of the creation or closure of school classes from the perspective of a distance indicator seldom found in the literature: the time needed to travel by road from the family home to the training establishment. Unlike classical deterministic schemes, the originality of this work lies in the use of simulations which take into account the randomness of students' locations to provide an indication of the variability of the optimal positions for the classes' creation or closure solutions. We illustrate this with two case studies on postcompulsory education in France.
\end{abstract}

\section{Introduction}

The organization of the map of education is a never-ending problem for the French administration. Every year, training establishments face the possibility of having to either create new classes or close others, or do both, depending essentially on whether the number of enrolments increases or decreases. These decisions are difficult because they depend on fluctuations in education demand, the determinants of which are not easy to identify and predict. However, there is one factor that is consensually recognized as playing a central role in students' choice of training establishment: the geographical distance that the family or student has to travel when commuting between home and school (Alm and Winters, 2009). "Aside from such traditional measures of benefits and costs like tuition, financial aid, and school quality, a crucial explanatory variable in our analysis is the distance from a student's home to the different ... state institutions. Our empirical results indicate that student intrastate migration is strongly discouraged by greater distance" (page 728). Indeed, distance plays a major role in commuting tolerance (Clark et al, 2003) and in a more extensive consideration in all types of migration, as geographical mobility is costly (Lemistre and Magrini, 2010).

Very few studies have been carried out concerning the related problem of the location-allocation of schools linked to students' commuting distance. And when this has been done, the question is related to that of the creation or closure of classes with a consideration of distance as the major determinant (Cahuzac and Tahar, 2000; Hastings et al, 2005; Müller et al, 2008) for both compulsory or postcompulsory education. Therefore, it is not surprising to observe that public authorities base their 
decision to create or close classes on household location: that is on the distance separating students from schools.

This question of the creation or closure of classes is all the more relevant as public authorities are faced with growing budget constraints and consequently have to rationalize the organization of the training supply and, more precisely 'optimize' its spatial distribution. This is particularly true in the case of agricultural education in France. Its budget has decreased dramatically as a result of the decline in the number of students over the last ten years. This crisis leads to a complete revision of the map of agricultural training sites in French regions (Férat, 2006).

Facing this problem, the objective of this study is not to determine the factors affecting education demand, but rather to propose a decision-aid tool which is intended to optimize the class-creation or class-closure decision based only on students' location. The distance indicator we use is the time needed to travel by road from the family home to the training establishment. This distance-time indicator makes it possible to describe more accurately the students' conditions of access to their school. This problem is studied for two cases of postcompulsory education in agricultures. These two cases have been submitted by the Agriculture Government Board for the Midi-Pyrénées Region (in southwest France): one a Baccalaureate-level training and the other a post-Baccalaureate training.

After briefly reviewing the literature on the role of distance in education-related mobility, besides other considerations, we propose a mathematical program for the resolution of the problems related to the creation or closure of classes on the basis of distance. This program involves simulations of populations of students from a model adjusted for the observed localizations of the students. The originality of this study lies in the fact that we use a mathematical model in which points are distributed randomly in space [the point process model (see Bonneu and Thomas-Agnan, 2009; Diggle, 2003)] to simulate the students' location. Our model is estimated using the current observed locations of the students, and enables us to generate several student-population scenarios and to solve the class-creation or class-closure problem for each scenario. The optimization is based on a criterion of minimization of the distance-time indicator and is performed using a heuristic algorithm that provides approximate solutions. This approach has the main advantage of taking into account the randomness of students' locations: indeed, our data concern a given year (2007) and a purely deterministic approach would ignore the fact that other years could yield different patterns. On the contrary, our simulation approach allows us to reproduce this unobserved randomness in a way which is faithful to the observed data and thus provides an indication of the variability of the optimal positions for class creation or closure.

\section{The major role played by distance in education demand}

The few studies conducted on the subject show that the process through which students choose which training to carry out is determined by two main considerations. ${ }^{(1)}$ The first main consideration concerns the geographical proximity to the student's home of the site where the training will take place, or its accessibility. The second major consideration seems to be the level of excellence or success rate achieved by the school's students (Alm and Winters, 2009). The students perceive these levels differently depending on, for example, their social origin or past school results. The different determinants of education demands have been analysed recently by Stair et al (2006) by considering the willingness to pay for improvements in the quality of local public education; their

(1) Müller et al (2008) for a case study in Germany; Cahuzac and Tahar (2000) for a case study in France; Hoxby (2003) and Manski and Wise (1983) for studies of North American cases. 
paper can be considered to be an overview of the determinants influencing education demand. Here we give a brief summary of the literature, focusing only on the crucial influence of distance in education demand, regardless of other considerations.

\subsection{Choosing a training course and choosing a training site: the importance of distance}

The authors who have written on the subject tend to distinguish two steps in the choice process: the choice of a training course or qualification; and the choice of a school or training site that will provide the training. The question is, which choice comes first? Do the student and his or her family first decide what type of training they wish to undertake and then look for training establishments that provide the chosen training? If so, they may then choose the establishment that is closest to home. Or, on the contrary, do they first decide which establishment the student should go to - possibly taking the distance into account - and then select one of the training courses offered by the establishment in question? The literature shows that both scenarios occur and that distance appears as an important factor in the two cases (Alm and Winters, 2009). The first scenario seems to be the more frequent, although ultimately it is difficult to distinguish one from the other.

\subsubsection{Choosing the training site before choosing the training}

In the case of both compulsory and postcompulsory vocational education, the study conducted in France by Larceneux (1997) on the wishes of students' parents shows a certain 'inertia' in education-related mobilities, in that the parents tend to choose a training establishment that is geographically close to their home, and then select one of the training courses offered by the school in question. Distance therefore plays a dominant role.

This finding is corroborated by Arrighi's study (2004) which shows, for instance, that future education paths of children living in rural areas is decided very early on according to the local supply of training. Indeed, rural children are more numerous in vocational training; and yet Arrighi found that "if the student's level of school performance were the only criterion taken into account, the proportion of rural youth who attend general education schools would then be equal to that of urban youth" (page 69). According to Arrighi, an explanation for this finding is that it is very important for rural families to ensure that in the future their offspring remain geographically close to the family home. Therefore, rural families tend to choose the vocational training courses that are offered locally and that are more adapted to the rural world. Studies conducted by a sociologist (Grelet, 2004; 2006) also confirm that geographical proximity is a strong determinant, by showing that the training options that young people choose are no more than the reflection of the training supply available locally even for postcompulsory education.

\subsubsection{Choosing a training option and then choosing the training establishment}

Continuing in the footsteps of Fourcade and Ourliac (1983) — who have also shown that students' education-related mobility is relatively low-Cahuzac and Tahar (2000) focus more specifically on the case of BEP (second diploma) training (ie, term class of compulsory education, see figure A1 in the appendix) in the Midi-Pyrénées Region of France. They observe 7000 young individuals aged, on average, 16 years and attending 94 education establishments called 'lycées'. They show that the choice of training and the choice of training establishment are strongly interdependent and that distance is an essential decision-making criterion (distance 'as the crow flies'). They find that $68 \%$ of the students are enrolled in schools located less than $20 \mathrm{~km}$ from their home and that $83 \%$ attend schools that are situated less than $30 \mathrm{~km}$ from their home. 
They also examine the choices expressed by the students prior to their actual enrolment. In cases where the students apply for the same training courses in all the educational establishments, it appears that for almost $50 \%$ of the students, their firstchoice training site is closer to home than their second-choice; and that for $30 \%$ of the students the distance separating the first-choice school from home and that separating the second-choice school are equivalent. In cases when the students apply for different training courses in their list of choices, for $70 \%$ of them the distance separating the different training sites from home are equivalent; and only $13 \%$ of these students have a first choice located further away from home than their second choice. Thus, whether one looks at the students' wishes or their current enrolments, one finds that a large majority of students prefer the training sites that are the closest to home. Above all, the authors conclude that once the students have chosen the type of training they want to pursue, they then choose the closest training site as their priority choice.

This idea is also found in the study conducted in Germany (city of Dresden with 14000 students enrolled in 23 schools) by Müller et al (2008) who observe that most students aged between 10 and 19 years are enrolled in the school that is closest to their home (2) for a given type of establishment. "Students attending schools with a common profile mostly are located in the surrounding catchment area. Thus, one could assume that proximity is an important factor for school choice" (Müller et al, 2008, page 5), although, in the area observed, no allocation rule is applied by the city's administrative authorities. The fact that a large number of students $(80 \%)$ do not actually choose the school that is the nearest to home, but rather the school closest to home from among those with a similar profile ( $70 \%$ of these students), reinforces the idea that families and their children choose a type of training first, and then a training site, and not the other way around. Furthermore, the fact that the distances separating the schools from the students' homes are relatively small tends to indicate that the students choose one type of training among the types offered by the schools situated within a threshold distance. The student's family has probably considered this threshold distance as the maximum distance they can travel daily. Therefore it is difficult to sustain the idea that the preferred training course is chosen independently of the distance criterion.

Thus, among the training selection criteria, distance appears to be a major determinant. All these results show that the distance, or geographical proximity, plays a fundamental role in the choices of either or both the training program and the training establishment, whether the choice of training is made before the choice of school or vice versa. This influence of distance is explained partly by transport-cost considerations. Indeed, Combes and Lafourcade (2005) have shown that in France there is a strong correlation between the geographical distance or the time of transport and the costs of transport.

Given that the data we use concern general, and relatively unselective postcompulsory, agricultural training programs, distance is expected to play a correspondingly important role in the student's choices. In the next section we examine our dataset and measure the proportion of students who have selected the training sites that are the nearest to their home. For this purpose, rather than using the Euclidean distance as the crow flies, which is often used as a proxy, we use a distance-time indicator. Indeed, as explained by Hilal (2007), it is the time of access to services that matters, rather than a kilometric distance: "people moving attach more importance to the access time than the distance in kilometers" (page 42). By considering the national data on daily commuting for work or for study, Hilal calculates road distances

(2) In Müller et al (2008) the distance observed is the (metric) distance of the shortest route between the home and school. 
expressed in time by finding the route, from one town to the other for each pair of towns in France, which takes the shortest time to travel taking into account the geographical environment and traffic conditions. Thus, this distance-time indicator reflects more accurately the real conditions of access, which vary according to the type of town considered. For instance, in urban areas, a short geographical distance as the crow flies may actually take a long time to cover depending on road-congestion situations. Sometimes, the same applies to rural villages: a natural obstacle may separate two villages (a mountain, for example) and travelling from one to the other may actually take a long time. ${ }^{(3)}$

Following Hilal, we propose to use this time-travel index to analyze commuting for study. Moreover, this hypothesis can be supported by other studies underlining the importance of car use in commuting (Kenworthy and Laube, 1999). And for France in particular, Hubert (2009) notes that the car still is the most used mode of transport with a rate of $60 \%$ in urban areas and $80 \%$ in rural areas. Finally, one could also note that, in general, the mode of transport is a bus for students using school transport, then a car.

\section{Data and the impact of distance in French agricultural education}

The database provided to us by the French Ministry of Agriculture contains the location of training sites and agricultural students in the Midi-Pyrénées Region during 2007. These locations are identified by the longitude and latitude of their town center in the Lambert II coordinates system. The geographic level of granularity is rather high but our simulation method (presented in section 4) takes into account this location error and yields more realistic patterns of students. In this section we report the allocation map of students to their establishments by a matrix of distance-time measures. This allows us to judge the importance of this indicator with regard to the final allocation of students to establishments during 2007 . We find that the distance-time measure is a predominant factor for students in choosing their training establishment. Subsequently we use the coordinates contained in the database (the matrix of distance-time measures) to fit our probabilistic model and to allocate the distance-time indicator between the simulated locations of students and the real training establishments.

We start by presenting the distances-times between the training sites currently chosen by agricultural students enrolled in the Midi-Pyrénées Region at the beginning of the 2007 school year (September), under the hypothesis that most of these students use transportation by road to reach their training site. ${ }^{(4)} \mathrm{We}$ end this section by providing a brief description of the two case studies used to address the problems of class creation or closure in the agricultural training system in the Midi-Pyrénées Region. ${ }^{(5)}$

\subsection{National Education versus Agricultural Education}

The education system in France is divided into three stages (see figure A1): primary education (pupils aged from 6 to 10 years, on average), secondary education (pupils aged from 11 to 18 years), higher education [beginning after the Baccalaureate diploma (Bac) and which validates the end of secondary education and is necessary to attend higher education]. Primary and secondary education constitutes compulsory education

(3) For more details on Hilal's method of calculation see Hilal (2007, page 44).

(4) The influence of transport mode on school choice is beyond the scope of this paper.

(5) The data are supplied by the Ministry of Agriculture, and more precisely by the regional board of the Ministry in the Midi-Pyrénées region which records, each year, all the students enrolled in agricultural training in the region. The data used are for the school year 2007. 
(school is compulsory in France until 16 years of age). The different types of classes and diplomas relative to the different ages of pupils are presented in the appendix (figure A1). Education has both public and private establishments but is predominantly public.

The Ministry of National Education regulates all the (national) French education system, but the Ministry of Agriculture supervises the programs and institutions for agricultural training. More precisely the Agricultural Education system corresponds to the National Education system (figure A1), and so, all the agricultural training diplomas have a name corresponding with those of the National Education system, but a specific identification is added for agriculture fields of study. For instance, in one of our case studies the students are studying for a BTSA qualification, that is, they are attending a National Diploma (BTS) course in agricultural topics (A).

These agricultural training courses are given in specific schools that belong to the Ministry of Agriculture and not the Ministry of National Education. This separation is due to historical factors. The Agricultural Education system (AE) is the outcome of a long French tradition that started in 1848 with the creation of the first 'school farms'. Linked to the Ministry of Agriculture, the AE has been, and continues to be, a driving force of modernization and development of French agriculture. The AE was for a long time aimed at children of farming families, and it has helped the gradual modernization of the skills of people working on farms that were mostly family operated. From the 1950s onwards, in an attempt to compensate for the progressive decline in the number of farmers, the AE was able to diversify its supply of training and attract new kinds of recruits into the profession. It now offers a full range of training programs covering production, transformation, and service-related skills meant for students of all levels from the 4th class to post Bac levels (see figure A1). The agricultural training course offered by the $\mathrm{AE}$ are in both general education and vocational training programs.

\subsection{The importance of distance in the choice of these students}

The Midi-Pyrénées [figure 1(a)] is one of the regions in France that has the highest number of agricultural students. The region comprises 3019 towns or villages, 43 of which have establishments of compulsory and postcompulsory agricultural training (from the 4th class of secondary education to Bac +2 years of higher education; please see figure A1 for more details on the French education system). In September 2007 these towns with agricultural schools had over 10000 agricultural students, $90 \%$ of whom originated from the region. In this study we only consider the students who are resident in the region. ${ }^{(6)}$ Figure $1(\mathrm{~b})$ represents the distribution of agricultural schools across the region.

With regard to the time needed for students to travel to school by road, we observe that three quarters of all students live less than $25 \mathrm{~min}$ from an agricultural school (table 1). However, as we shall see below, these findings do not take into account the specificity of the training courses offered by the different training sites. Indeed, the agricultural schools in the region offer a total of seventy-four qualifying training programs. ${ }^{(7)}$

(6) The calculations of the distances will as a result be more homogeneous; indeed some students come from distant regions and even countries, which would considerably increase the average distances.

(7) Each training program is identified as a National Education diploma with a specialty developed by the AE. 

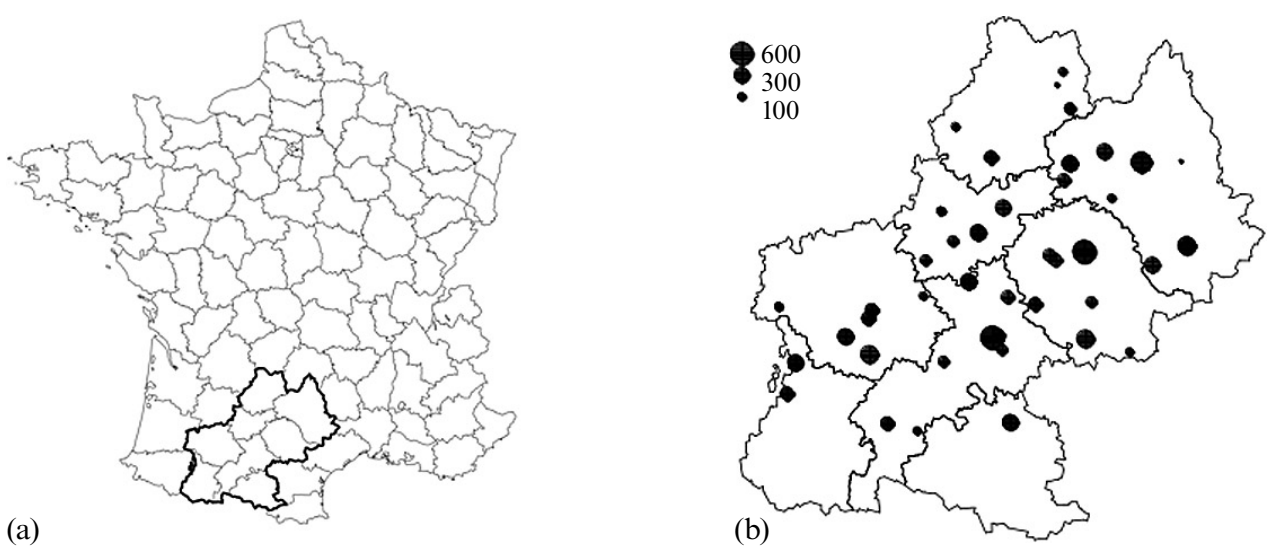

(a)

(b)

Figure 1. Distribution of students across the forty-three towns equipped with agricultural school in the Midi-Pyrénées Region (2007): (a) the Midi-Pyrénées Region in France is divided into eight administrative zones (departments); (b) the agricultural training sites throughout the Midi-Pyrénées Region, proportional to the number of students enrolled in 2007.

Table 1. Percentage of the students living in the vicinity of an agricultural training site.

\section{Existence of a training site Cumulated \%} situated:

\begin{tabular}{ll}
\hline In the same municipality & 13 \\
Less than $10 \mathrm{~min}$ away & 24 \\
Less than $20 \mathrm{~min}$ away & 60 \\
Less than $30 \mathrm{~min}$ away & 83 \\
Less than 40 min away & 96
\end{tabular}

In view of the results of existing studies presented above, we propose to observe the distribution of students according to distance, and to evaluate the percentage of students enrolled:

(1) in the training establishment that is closest to home, regardless of the training course chosen;

(2) in the school which, among other schools offering the type of training chosen by the student, is the closest to home.

We present the results according to two distance criteria: a distance in kilometers as the crow flies and a distance-time indicator evaluated as the time needed to travel by road from home to school. Both distances are calculated between two central points: the town hall of the town where the school is situated and the town hall of the town where the student lives (ie, his or her parents' home). More precisely, the distancetime indicator we use is the time needed to travel by road, at rush hour, from one point to the other. When the establishment is located in the town where the student lives, the geographical distance or travelling time takes value 0 . As mentioned in the previous section, this road distance, expressed in terms of time, seems to be a better proxy than the distance in kilometers generally used in studies on this subject.

The percentage of students who are enrolled in schools nearest to home, among those that offer the type of training the students chose to pursue, is only significant if the type of training the students want to follow is offered by other schools; in which case, the student has to choose which school he or she prefers. Very few students only have one possible choice of school for their selected training course $(8.5 \%$ of the students). In these cases, the type of training chosen is highly specific and, incidentally, 
a large percentage of the student enrolled for the training in question come from other regions. ${ }^{\left({ }^{8}\right)}$ In fact, most students have several choices: $2-8$ sites for $36.5 \%$ and $9-35$ sites $^{(9)}$ for $55 \%$.

Furthermore, an important characteristic of AE, in comparison with National Education system, is that all its schools offer boarding facilities. Thus, 56\% of all the students enrolled in agricultural training schools are boarders. However, the percentage of boarders varies according to the diplomas for which they study. These differences might be explained by the age of the students. A priori, one could think that boarding modifies the influence of the distance criterion since it implies that the student no longer needs to travel to and from school daily. However, a large number of boarders go back home every weekend. Thus, distance still plays a role, albeit a lesser one than in the case of weekday boarders or day students (table 2).

Table 2. Percentage of students enrolled in the school nearest to their homes.

\begin{tabular}{|c|c|c|c|c|c|c|}
\hline & \multicolumn{3}{|c|}{ Distance as the crow flies } & \multicolumn{3}{|c|}{ Distance-time } \\
\hline & $\begin{array}{l}\text { all } \\
\text { students }\end{array}$ & $\begin{array}{l}\text { weekday } \\
\text { boarders } \\
\text { or day } \\
\text { students }\end{array}$ & $\begin{array}{l}\text { full } \\
\text { boarders }\end{array}$ & $\begin{array}{l}\text { all } \\
\text { students }\end{array}$ & $\begin{array}{l}\text { weekday } \\
\text { boarders } \\
\text { or day } \\
\text { students }\end{array}$ & $\begin{array}{l}\text { full } \\
\text { boarders }\end{array}$ \\
\hline $\begin{array}{l}\text { Percentage of students } \\
\text { enrolled in the school } \\
\text { nearest to home }\end{array}$ & 27 & 46 & 13 & 26 & 44 & 12 \\
\hline $\begin{array}{l}\text { Percentage of students } \\
\text { enrolled in the school } \\
\text { nearest to home among } \\
\text { those that offer the } \\
\text { selected type of training } \\
\text { (calculated only for the } \\
\text { students who have chosen } \\
\text { a type of training that is } \\
\text { provided by several } \\
\text { schools) }\end{array}$ & 60 & 79 & 46 & 61 & 79 & 47 \\
\hline
\end{tabular}

Table A1 in the appendix gives more details for the two training courses considered in our case study. The last column of this table shows that the majority of sites have a large proportion of full boarders attending the closest school.

The obtained results show firstly that, overall, using one or the other distance indicator (crow flies or time) leads to comparable conclusions and confirms the results of existing studies: for a given type of training, most of the students are enrolled in the school closest to home. The rate is highest for nonboarders (students who are not full boarders) $(70 \%)$. As the distance-time indicator remains a better indicator of the conditions of access to school (Hilal, 2007), we use the distance-time indicator only, in the remainder of this work.

(8) One third of the students following these specific training courses (offered by only one school in the area) are not from the Midi-Pyrénées Region. In contrast, students from other regions only represent $10 \%$ of the population of other schools.

(9) The maximum number of sites offering the same training option is 35 . 


\subsection{Time needed to travel from home to school}

If we consider the travel time for the students enrolled in their nearest schools - among those offering the type of training chosen - the average time is $37 \mathrm{~min}$ (between $30 \mathrm{~min}$ and $47 \mathrm{~min}$ for nonboarders and full boarders, respectively). More specifically, half the students are enrolled in a school that is located less than $30 \mathrm{~min}$ from their home (figure 2); the percentage increases dramatically for nonboarders $(70 \%)$ but drops to approximately $33 \%$ for full boarders.

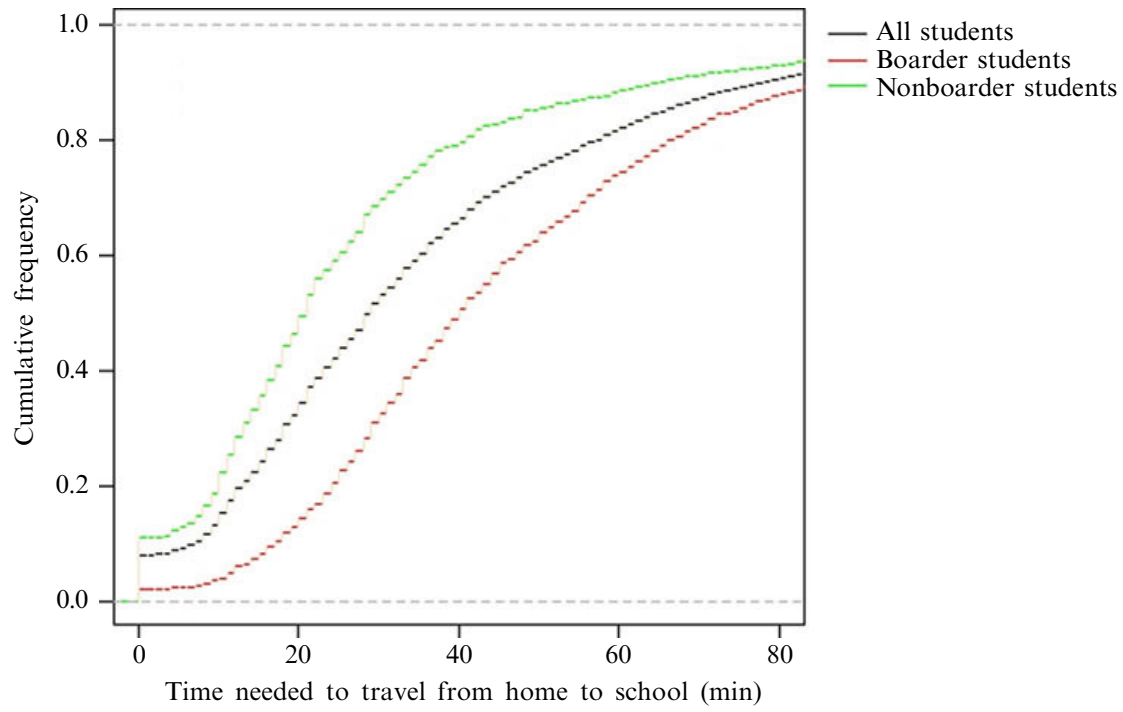

Figure 2. [In color online.] Students enrolled in the school closest to home among those that offer the type of training chosen by the student.

These results are comparable with those of Hilal (2007). His study shows that in France, students aged between 7 and 18 years need on average $23 \mathrm{~min}$ to travel to or from school ( 9 min for children aged between 7 and 15 years). ${ }^{(10)}$ The author also observes that students aged 15 years and above tend to spend more time travelling (to school) than economically active individuals, the latter needing on average $17 \mathrm{~min}$ to travel from home to work. Finally, he shows that the larger the distance between a town and the nearest urban center the longer it takes, on average, to travel to various facilities. Thus, he finds that the average time needed to travel to school is $20 \mathrm{~min}$ for students living in urban areas, against $30 \mathrm{~min}$ for those living in rural areas. Although the training site chosen here is the closest to home, our results show that the time needed to travel to school is, overall, longer for students. This might be due to the high percentage of students coming from rural areas ( $47 \%$ of all students).

In short, and although other factors deserve to be considered and investigated, ${ }^{(11)}$ our results - just like those of other studies on the subject - show that most students are enrolled in the school, among those that offer the chosen training course, that is nearest to home. It is on the basis of this hypothesis that we propose to solve

(10) These transport times were calculated by the author on the basis of the declarations made by individuals concerning their place of residence and the place where they perform their daily activities. In the case of young people, the activities in question are education-related activities.

(11) As mentioned it is difficult to determine the reasons clearly-other than those related to distance - why students choose either particular training courses or to study at particular schools, or both. Many explanations might exist and no other information is available at present. 
the problem of class creation and closure for two cases of postcompulsory training presented below.

\subsection{The two case studies}

\subsubsection{Case 1}

The BTSA ACSE is a two-year training course available to students who have obtained the Bac (please see figure A1). It leads to an advanced diploma (BTS) in agriculture (A) with a specialty entitled analysis and management of a farm (ACSE). Most of the students following this training program intend to become farmers, or technical consultants on farms or in professional organizations. In the Midi-Pyrénées Region just over 300 students are enrolled in this training program, $80 \%$ of whom are from the region. The program is available at eight different agricultural schools in the region. Because most of the students in this training course are aged 18 years or over, few of them are boarders (18\% of the first year students). Over half the students attend the school that is the closest to their home. The numbers of students enrolling in the BTSA ACSE training program, which has been available for 10 years, increased steadily until the early 2000s, and then stabilized and even declined by $2 \%$ between 2006 and 2007. This relative lack of attractiveness, in comparison with other more popular training courses, caused the Regional Government Board (RGB) to have one of the schools in the region discontinue the course.

\subsubsection{Case 2}

The Professional Baccalaureate in Services for Rural Areas program (Bac Pro) is also a two-year training program available immediately after the end of compulsory education. The average age of students is 18 years and just under 500 students from the region are enrolled in this training program, in eight different schools. The students are younger than those in the BTSA ACSE program and half are boarders. The percentage of students who are enrolled in the school that is the closest to their home is higher than in the case of BTSA ACSE students: $85 \%$ of the first-year and second-year students. This training program has been available since 2005 , initially in six schools and in two additional schools in 2006. The sharp increase in the number of students enrolled in the program has caused the RGB to create a class in another school.

Insofar as it would make no sense to close or create a second-year class, ${ }^{(12)}$ we propose to examine the two problems on the basis of an observation of first-year students only (see appendix for detailed information), and to use the criterion of minimization of the distance-time indicator to help us to evaluate in which school a class should be eliminated or created. The originality of our approach to these problems is to introduce a random dimension to the students' residence location as explained in the following section.

\section{Methodology and results of the model of students' geographic distribution and of the decision to close or create classes}

In this section we present the methodology used to decide in which school these two training courses (BTSA ACSE and Bac Pro) should be eliminated or offered. We propose to make this decision on the basis of the criterion of minimization of the total distance-time travelled to school by all the students (see subsection 4.2). This criterion is applied to a series of simulated student populations based on real data for the year 2007. The decision to minimize the total distances travelled loses its interest if this

(12) Indeed, if a second-year class was closed, then the first-year students would not be able to complete their training. Similarly, creating a second-year class makes no sense if a first-year class was not created beforehand. 
criterion is applied only to the student population of one given year, thus our decision would appear arbitrary. In the absence of data related to other years, we propose to simulate several scenarios of student populations that could occur. For this purpose we generate the positions of different populations of students using a model of random distribution of points in space, estimated on the basis of real data concerning the students enrolled in the two training courses in question in 2007. Similar approaches have been developed for optimizing the location of a fire station (see Bonneu and Thomas-Agnan, 2009). Among the possible models for such patterns (Diggle, 2003) we have chosen a simple model: a Poisson point process model (Bonneu, 2007) (see the next subsection). Finally, after indicating how we evaluate the robustness of the solutions found for the creation or closure of classes problems (see subsection 4.3), we present and comment on these results.

\subsection{Modelling the geographic distribution of the students}

Using geomarketing software (eg, Geoconcept, see http://www.geoconcept.com) can solve some problems related to the optimal geographic distribution. These tools can be used, for example, by a travelling tradesman to determine the optimal route between each client he needs to visit according to the geographic location of the latter. But these problems are addressed on a 'day-to-day' basis using real data, rather than stochastic data to account for the variability of the data. The type of problem we seek to solve here (the decision to create a new class or close an existing one) is made as one unique solution that will be enforced for a few years, although the number and the position of the students may vary from year to year. Thus, our aim is to determine the 'optimal' location of training facilities taking into account the random nature of students' residence location.

The stochastic nature of these points in space can be taken into account by estimating a probabilistic model. By indicating the town in which the student resides, our dataset contains information about the approximate location of the students. This specificity has led us to consider two possible modeling methods.

The first approach is discrete and considers that for each town the number of students is the realization of a Poisson random variable. A natural estimation of the expectation of this variable would then be the number of students living in that town. This method has the major drawback of not enabling us to obtain, during our simulations, students located in town in which there were no students in 2007. Moreover, this method does not take into account the location error made in the database by arbitrarily allocating students and establishments at the town center. The modeling approach described below has the advantage of giving more realistic simulation patterns in the sense that we do not have replicated locations of students. In simulations the students are located in their town but not exactly (and wrongly) at the town center.

The second method, which we finally decide to use, is based on the theory of spatial point processes often used to model a set of random points in a space $\Omega$ with a dimension $d$. In our case the observation area $\Omega$ is the Midi-Pyrénées Region where $d=2$ (each point is identified by a longitude and latitude coordinate on the map). Contrary to the common context in which locations are considered as several independent realizations drawn from one random variable, spatial point processes have two advantages: they take into account the random distribution of the number of points and the possible spatial autocorrelation between these points. These characteristics and the large number of spatial point process models justify their being used more and more frequently in many different fields such as astronomy, ecology, forest management, spatial epidemiology, and image analysis.

The most basic of all point processes is the Poisson point process which models a random distribution of points without interaction: that is, the points are located 
independently of each other. These processes are identified by their intensity function $\lambda$ or by the corresponding intensity measure $\mu$ defined in any subregion $B$ of $\Omega$ :

$$
\mu(B)=\int_{B} \lambda(s) \mathrm{d} s, \quad \forall B \subset \Omega .
$$

Heuristically, $\lambda(s) \mathrm{d} s$ is the probability for the occurrence of a point in a small ball with center $s$ and volume $\mathrm{d} s$. Then $\mu(B)$ determines the expected number of points in the region $B$.

For $0<\mu(B)<\infty$, a Poisson point process $X$ is characterized by the random variable $N(B)$ of the number of points in $B$ for the process $X$ which is distributed as a Poisson distribution of mean $\mu(B)$ :

$$
N(B) \sim P[\mu(B)], \quad \forall B \subset \Omega .
$$

In the Poisson point process framework, we can make a link between the intensity and the density function defined for a random variable. Indeed, $\left[X_{B} \mid N(B)=n\right]$ is a process that produces $n$ independent and identically distributed realizations of the random variable of density $f(s)=\lambda(s) / \mu(B)$ for all $n \in N$ and $B \subset \Omega$ (where $X_{B}$ is the point process restricted to subset $B \subset \Omega$ ).

The last property shows the relationship between the intensity of the Poisson point process and the $d$-dimensional density $f$ defining the distribution of the locations $S_{i}$ conditionally to the number of points $N$ :

$$
\forall s \in \Omega, \quad f(s)=\lambda(s) / \int_{\Omega} \lambda(s) \mathrm{d} s .
$$

Note here that Poisson point processes belong to two families of point processes: Cox point processes and Markov point processes, which also contain other processes modelling interactions (aggregation and repulsion) between points. But since interaction is not dominant in our framework, we have restricted our choice to the Poisson point process that does not take interactions into account (see, eg, Bonneu, 2007; Diggle, 2003; Moller and Waagepeterson, 2005 for an application).

Thus, for the problem we are considering here, we assume that the students' places of residence are the realization of a Poisson point process which allows us to simulate the students' positions independently of each other, ${ }^{(13)}$ based on the estimated intensity of the population of students. The intensity, estimated using a nonparametric kernel method (see, eg, Diggle, 2003) enables us to take into account the inhomogeneous distribution of the students on the territory. The choice of a kernel function with infinite support presents a considerable advantage over the discrete approach. Indeed, the intensity may be low but never null in towns in which no students were found in 2007. This specificity is important because it corresponds to a reality about the evolution of students' residence locations. Color plates 1 and 2 show the current locations of the first-year students for each of the training courses examined, and the estimated intensity. ${ }^{(14)}$

(13) The Poisson point process is based on the hypothesis of independence. This hypothesis corresponds to the plausible hypothesis that having other students living nearby does not influence the enrollment of a student in one particular school. Furthermore, this hypothesis allows us to choose a simpler model that enables us to avoid important calculation complications.

(14) Note that migration flows could perturb the results: for instance, if there is a strong migration to other areas around the location where it is intended to add a new class. But in our case studies, migration and population fluctuations over time are small, mainly due to a stable renewal of generations and education demand over time, according to the RGB. So, with small migration flows we can assume that the distribution (density) of students is small, even if the overall number if modified. In other words, if the intensity of students remains stable, the solution will be unchanged. We do not present detailed data to verify this point. 

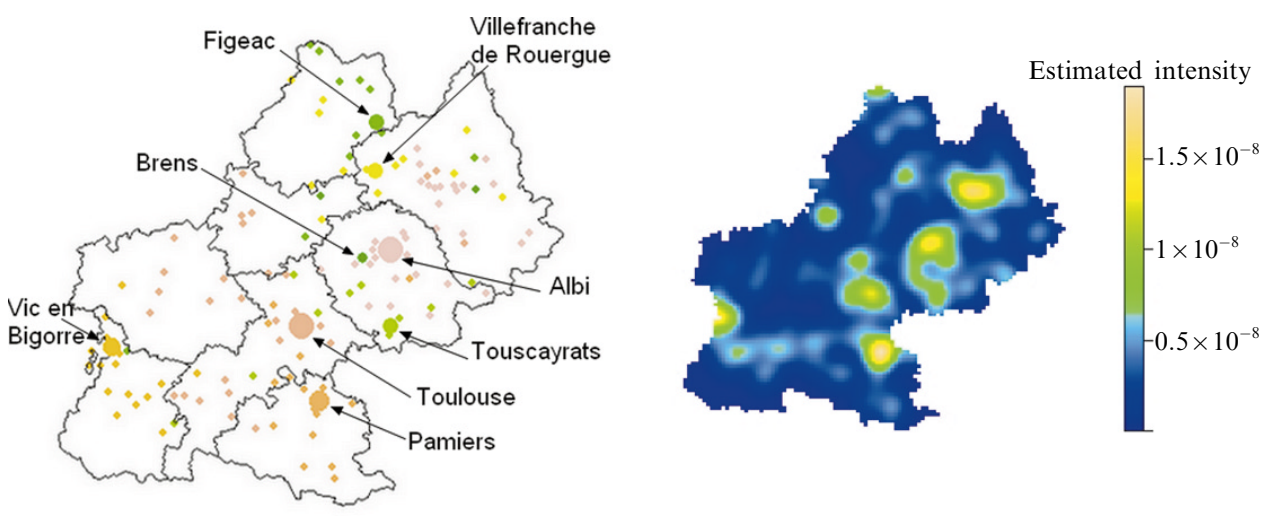

Color plate 1. Sites and origins of the 2007 BTSA ACSE (National Diploma in Agriculture: Analysis and Management of a Farm) students.
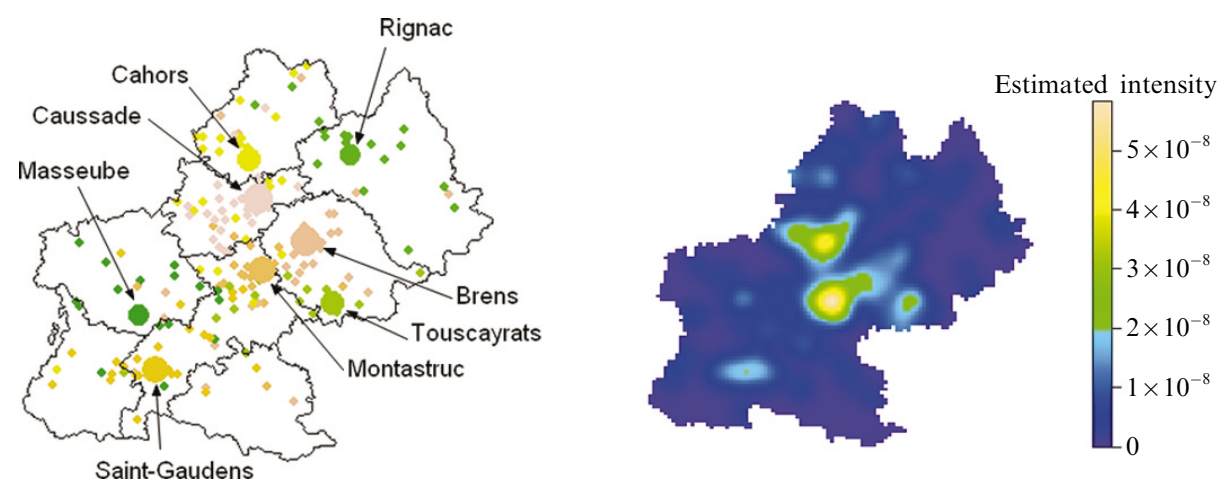

Color plate 2. Sites and origins of the 2007 Bac Pro (Professional Baccalaureate in Services for Rural Areas) students.

This method enables us to simulate new populations of students for which we evaluate different scenarios involving the creation and closure of classes. These simulated populations are calibrated on the data for 2007 and reflect expected short-term fluctuations of the location of the student population. Taking into account long-term trends would require a more complete dataset with a time dimension.

\subsection{Methodology for deciding to create a new class or close an existing one, based on distance - time}

Different scenarios of class creation and closure are evaluated using a criterion of minimization of the sum of distances separating the students' homes from their schools. This sum of distances is calculated for each random generation of students estimated by the Poisson point process. The calculation of the distance-time indicator using the simulated data necessitates an intermediate stage between the simulation of a cohort of students and the calculation of the objective function of the optimization.

Indeed, the distances - times were calculated beforehand between all the towns and villages of the Midi-Pyrénées Region in which students live and those equipped with agricultural schools, and were then stored in a $3019 \times 43$ matrix. Therefore, before reporting the distance-time needed for each student to reach a town equipped with an agricultural school, we have to identify the town that is closest to the simulated location of the student. To do this we consider distance as the crow flies: the closest town to the simulated location of the student is identified as his or her home town. 
This estimation method makes sense and is easily justified. For example, for a city as large as Toulouse (the region's capital), this estimation method takes into account the fact that a student living in a peripheral area of the city often lives closer to a suburban town than to the centre of his or her city of residence. We then compute the sum of time-distance for each problem.

\subsubsection{Minimization of the sum of the distances - times and the closure of classes}

Each of the eight schools offering the BTSA training course (one class per site) is liable to be forced to close one class. We therefore calculate the sum of the distances separating the students' homes from their schools, for each possible case of class closure among the eight schools offering the BTSA training course. For the students belonging to a class which has been closed, the sum of distances is recalculated after each student has been reallocated to the nearest possible school among the seven remaining ones. The RGB specified that the number of students per class must not exceed thirty two. Thus, a student is assigned to the nearest school respecting this threshold of thirty-two. Our algorithm takes this constraint into account.

\subsubsection{Minimization of the sum of distances and the creation of classes}

Schools in eight different towns provide the Bac Pro training and each of them has only one class for the first-year training. The cost of creating a new school being extremely high, the RGB chooses to open new classes in the existing schools. Let us note that a new class could also be created in a school that already offers this training program, in which case, the school would have two classes for the same training. But for the sake of territorial equity, the RGB prefers to create new Bac Pro classes in schools that do not already offer this training program. The objective, therefore, is to determine in which school-among the thirty-five schools that do not already provide this training course - a new class should be created. For this purpose, we evaluate the sum of distances separating the students from the nearest school for each of the possible scenarios of class creation among the thirty-five schools applying for the creation of a new class. We proceed as follows.

Creating a Bac Pro class in a school that does not already offer the training necessarily leads to the reallocation of all the students who have chosen this training among the nine schools (the eight schools in which the training was already offered and the one in which the class has just been opened). When this reallocation is carried out, the criterion of the maximum thirty-two students per class must be respected. Moreover, the minimum number of students - determined by the RGB - for the creation of a class is twelve. It is necessary to reach this minimum threshold before a class can be created. We have chosen to minimize the sum of distances among the schools that reach this threshold of twelve students. Let us note here that for this training course, we have observed that in a large number of schools the maximum number of thirty-two students per class is exceeded. The increasing demand for this training course has led the local authorities to come to terms with the fact that the maximum threshold is exceeded for some time until a new class is created. When the different scenarios are evaluated, the RGB can then privilege the site that minimizes the sum of distances, and that ensures a better-balanced student distribution.

\subsubsection{Results significance and classification}

After the simulations have been run, we conduct a statistical test to determine if the frequency of occurrence of a site as a solution to the class creation or closure problem is significantly different from randomness. The required statistical test is a proportion test. The proportion is the frequency of occurrence of the site as a solution to the problem among the simulations run. We assume that this proportion has a normal 
distribution with mean $p$ and standard deviation $[p(1-p) / n]^{1 / 2}$, where $n$ is the size of the sample observed, corresponding with the number of simulations.

For the class closure problem, we verify that this frequency is significantly different from that of a school chosen randomly from all schools offering the training course that are considered. Let $p_{0}$ be this theoretical probability of a purely random choice. As eight schools provide the BTSA ASCE training course, $p_{0}=0.125$ : each site has one chance in eight of being selected, during a random draw, to be the school that will have a class closed.

For the class creation problem, the theoretical probability changes. The aim is to determine in which school-among the thirty five that do not offer the training course - a new Bac Pro class should be created. Each of these schools has a theoretical probability $p_{0} \approx 0.028$ of being drawn as the school in which a class should be created.

As it is the sum of distances that is the determinant in the decision to open a new class or close an existing one, the possible schools are ranked according to that sum of distances-times. This classification is conducted for each simulation of student populations. From these classifications we compute occurrence frequencies for each school applying to create or close a class as a first-rank solution (the best solution), and a second-rank solution (the second-best solution). The school that occurs most frequently is considered as the solution to the problem. ${ }^{(15)}$

\subsection{The results}

Following this methodology, the different 'opening' or 'closing' scenarios were evaluated on the basis of 100 populations of students simulated using the adjusted Poisson point process. The computational algorithms we have developed were implemented with the open source R software [spdep package by Baddeley and Turner (2006)].

\subsubsection{Solution for the closure of a class in a school offering the BTSA ACSE training course}

We have evaluated each of the eight schools offering the BTSA ACSE training course. That is to say, we have eliminated each school one after another, reassigned the students to the remaining schools and calculated the sum of distances-times for each scenario. Table presents the results obtained after 100 simulations. We have run 200 new simulations and the same solutions were found.

Among the significant solutions, Verdalle has a very high percentage of occurrences at rank 1 with a very small gap separating it from that of Villefranche. It is interesting to note that thee two solutions also occur as rank-2 solutions and have the highest percentages of occurrence. However, at rank 2, the frequency of the school in Villefranche is higher than that of Verdalle. Ultimately, these two sites occur as the two 'best' solutions to the question of which school should close its BTSA ACSE class.

It is interesting to note that some schools never occur as 'solutions' (Pamiers and Vic en Bigorre). The schools located in these towns have the advantage of being situated in the most southern area of the region. Thus, the schools of Pamiers and Vic en Bigorre have wide catchment areas and suffer little competition from other schools.

(15) The final choice of solution among the schools that have significant occurrence frequencies could be determined by other considerations. For example, the choice might be made either by exclusively considering the frequency of the first-rank solutions or by taking into account both frequencies, that is, that of first-rank solutions and that of second-rank solutions. Concerning this point, we have not investigated ways of choosing a solution according to the different ranks held by the solutions. Further investigation into the possible use of a 'scoring' evaluation method would be useful for the development of this research. 
Table 3. Occurrence frequencies (at ranks 1 and 2) and $p$-value (proportion test) of schools for the closure of a BTSA ACSE ${ }^{\text {a }}$ class (100 simulations).

\begin{tabular}{|c|c|c|c|c|}
\hline \multirow{2}{*}{$\begin{array}{l}\text { Town in which a school } \\
\text { has a BTSA ACSE } \\
\text { class to be closed }\end{array}$} & \multicolumn{2}{|l|}{ Rank 1} & \multicolumn{2}{|l|}{ Rank 2} \\
\hline & $\begin{array}{l}\text { occurrence } \\
\text { frequency }(\%)\end{array}$ & $p$-value & $\begin{array}{l}\text { occurrence } \\
\text { frequency }(\%)\end{array}$ & $p$-value \\
\hline Brens & 8 & 0.2265 & 8 & 0.2265 \\
\hline Verdalle & 26 & $8.465 \times 10^{-5}$ & 20 & 0.3429 \\
\hline Albi & 13 & 1 & 11 & 0.7624 \\
\hline Pamiers & 0 & $2.851 \times 10^{-4}$ & 0 & $2.851 \times 10^{-4}$ \\
\hline Toulouse & 15 & 0.5453 & 17 & 0.2265 \\
\hline Vic en Bigorre & 0 & $2.851 \times 10^{-4}$ & 0 & $2.851 \times 10^{-4}$ \\
\hline Figeac & 15 & 0.5453 & 17 & 0.2265 \\
\hline Villefranche de Rouergue & 23 & $2.497 \times 10^{-3}$ & 27 & $2.304 \times 10^{-5}$ \\
\hline
\end{tabular}

a National Diploma in Agriculture: Analysis and Management of a Farm.

\subsubsection{Solution for the creation of a new Bac Pro class in a school}

The Bac Pro is offered in eight schools. We have evaluated each of the thirty-five other sites - one after another - in which a new Bac Pro class could be created. We have run 100 simulations in which we reassign the students to the nine schools (the eight existing ones + the new class); for each simulation we only retain the five sites that minimize the sum of distance-time. Table 4 gives the occurrence frequencies of the sites that occur at least once among the five best solutions during the simulations. Overall, we found that for rank 1, the same eight sites occur as solutions. For rank 2, we found the same eight sites and two additional ones that did not occur at rank 1.

Table 4. Occurrence frequencies (at ranks 1 and 2) and $p$-value (proportion test) for the creation of a Bac Pro ${ }^{\text {a }}$ class (100 simulations).

\begin{tabular}{|c|c|c|c|c|}
\hline \multirow{2}{*}{$\begin{array}{l}\text { Town in which a school } \\
\text { is to create a Bac Pro } \\
\text { class }\end{array}$} & \multicolumn{2}{|l|}{ Rank 1} & \multicolumn{2}{|l|}{ Rank 2} \\
\hline & $\begin{array}{l}\text { occurrence } \\
\text { frequency }(\%)\end{array}$ & $p$-value & $\begin{array}{l}\text { occurrence } \\
\text { frequency }(\%)\end{array}$ & $p$-value \\
\hline Cologne & 32 & $<2.2 \times 10^{-16}$ & 18 & $<2.2 \times 10^{-16}$ \\
\hline Donneville & 13 & $3.229 \times 10^{-14}$ & 11 & $4.484 \times 10^{-6}$ \\
\hline Toulouse & 20 & $<2.2 \times 10^{-16}$ & 24 & $<2.2 \times 10^{-16}$ \\
\hline Auch & 23 & $<2.2 \times 10^{-16}$ & 12 & $2.128 \times 10^{-7}$ \\
\hline Vic en Bigorre & 2 & 0.8303 & 6 & 0.1127 \\
\hline Sévérac l'Eglise & 6 & 0.1127 & 7 & 0.02877 \\
\hline Riscle & 2 & 0.8303 & 2 & 0.8303 \\
\hline Caussade & 2 & 0.8303 & 4 & 0.6996 \\
\hline Montauban & - & - & 5 & 0.3241 \\
\hline Tarbes & - & - & 11 & $4.484 \times 10^{-6}$ \\
\hline
\end{tabular}

Among the significant solutions, the schools of Cologne and Toulouse occur as the best solutions with high occurrence frequencies and indices of robustness. The third and fourth best solutions are Auch and Donneville. These four sites with the highest occurrence frequencies form a geographical triangle including Toulouse. This triangle seems to reveal that the attractiveness of these sites is due to the demographic weight of the capital agglomeration. 


\section{Conclusion}

Beyond the results obtained concerning the problem of class creation or closure, we wish to draw attention to the ultimate purpose of this research. These tools can only be used, we believe, as 'decision-aid tools' and cannot replace the judgment of the decision makers. Indeed, they can also take into account criteria that are less 'objectivable' or 'quantifiable' in the quantitative techniques we use. It is crucial that the different stakeholders account for the general environment in which the agricultural schools operate such as historical and sociocultural characteristics of the school area. Indeed, this tool only helps to shed light on one dimension of the education reality. The results we have obtained are therefore not meant to reveal 'the' solution to the problem, but to help understand one of its dimensions and in turn help the public authorities in their decision to create or close a particular class. In this case, we have chosen to put forward the distance criterion-more precisely the time needed to travel from home to school-which is a major determinant of school choices made by the students and their families.

Further research could therefore integrate other criteria so as to better take into consideration this 'reality' before deciding where classes should be opened or closed. Among the criteria that should be accounted for are: the presence or absence of boarding facilities in the school, the presence or absence nearby of a public transport station, continuity in the students' education processes (once the student has completed his current training course, whether or not the school offers him or her higher-level training courses), the localization of the teachers (closing a class implies that the teacher must be transferred to another school). All these criteria can either modify the current solutions or, on the contrary, reinforce them. For this reason, it is important to design indicators that can be integrated into the algorithms that have been generated and to develop a weighing system that will take each of them into account according to its level of importance. This process of multicriteria evaluation is, obviously, more complex to implement and, above all, it requires additional data that can only be obtained by conducting surveys on the determinants of students' choice. Another limitation in our study comes from the fact we do not have the data for students coming from outside the region. This introduces a possible edge effect but let us underline the fact that they represent $10 \%$ of the overall student population.

One of the main interests of this study is that it has used the point process method to take into account the random nature of the data. Other improvements can be made. One first possible path to improvement is to take into account the students' frequency by school. For this purpose we could use Gini or entropy indices to obtain a more balanced distribution of the students across the different schools. A second possibility would be to use a marked point process. In this case, each localization can be assorted with a set of variables of different types (eg, real, complete, Boolean). A possible improvement might be to attribute to each individual some characteristics such as the wishes he or she has expressed, the place of work of his or her parents, or the wish to be a boarder at a school. These additional elements would then lead us to consider the optimization of a more realistic function than that based only on the distance-time indicator. Another interesting improvement suggested by a referee would be to replace zero distance (the student lives in the school area) by a more realistic value such as a quarter of the diameter of the area. With more complete data including a time dimension, it would be possible to fit into the same framework more complex spatiotemporal models that would take into account the evolution of education demand and migration flows.

Finally, another possible improvement would be to combine these simulation techniques with other methods of optimization such as the multicriteria genetic 
algorithms [see, eg, Berro and Leroux (2006) for an application] developed by the IRIT (Toulouse Institute of Research in Computer Science). These learning-based techniques make it possible to explore a much broader solution space, particularly in the framework of the resolution of problems such as the reallocation of a training course among all the schools. Indeed, the number of possible scenarios becomes too high for the optimization methods used here.

Thus, there are many possibilities for further research and the results we have obtained here are but the first steps in a field that has been very little explored until now.

Acknowledgements. The authors wish to thank all those who have contributed to this study: the representatives of the Agriculture and Forestry Government Board of the Midi-Pyrénées Region; Mohammed Hilal, researcher at the UMR CESAER of INRA-Dijon, for providing us with the distance-time data; Geosignal of the BVA group for their computer-technology-related assistance; the Regional Council of the Midi-Pyrénées Region for financing the program of research on the representation and simulation of spatial data (Spatialize Programme). We also wish to thank Georges Maffre, Thomas Gagnaire, and Honoré Komol for their contribution, and three anonymous referees for their valuable comments.

\section{References}

Alm J, Winters J, 2009, “Distance and intrastate college student migration” Economics of Education Review $28728-738$

Arrighi J-J, 2004, “Les jeunes dans l'espace rural: une entrée précoce sur le marché du travail ou une migration probable" Formation et Emploi $8763-88$

Baddeley A, Turner R, 2006, "Modeling spatial point patterns in R" Case Studies in Spatial Point Process Modeling $18523-74$

Berro A, Leroux I, 2006, "A simulation of strategic bargaining within biotechnology clusters", in Handbook of Research on Nature Inspired Computing for Economics and Management Volume I Ed. J-P Rennard (Idea Group, Hershey, PA) pp 335 - 351

Bonneu F, 2007, "Exploring and modeling fire department emergencies with a spatio-temporal marked point process" The Case Studies in Business, Industry and Government Statistics (CSBIGS) Journal $1139-152$

Bonneu F, Thomas-Agnan C, 2009, "Spatial point process models for location-allocation problems" Computational Statistics and Data Analysis 533070 - 3081

Cahuzac E, Tahar G, 2000, "Offre scolaire et arbitrage formation-distance: le cas des BEP en Midi-Pyrénées" Les Notes du Lirhe number 311

Clark W, Huang Y, Whiters S, 2003, "Does commuting distance matter?: Commuting tolerance and residential change" Regional Science and Urban Economics 33 199-221

Combes P-P, Lafourcade M, 2005, "Transport costs: measures, determinants and regional policy implications for France” Journal of Economic Geography 5 319-349

Diggle P J, 2003 Statistical Analysis of Spatial Point Patterns 2nd edition (Oxford University Press, Oxford)

Férat F, 2006, "L'enseignement agricole-une chance pour l'avenir des jeunes et des territoires" Rapport d'Information du Sénat no 27 http://www.senat.fr/rap/r06-027/r06-027_mono.html

Fourcade B, Ourliac G, 1983, "Localisation des formations, recrutement et insertion des élèves: un essai de mise en relation, le cas des formations techniques courtes en Midi-Pyrénées" Economie Méridionale 123

Grelet Y, 2004, "La reproduction sociale s'inscrit dans le territoire" Formation et Emploi 87 79-98

Grelet Y, 2006, "Des territoires qui façonnent les parcours scolaires des jeunes" Bref 2281 - 4

Hastings J, Kane T, Staiger D, 2005, "Parental preferences and school competition, evidence from a public choice program", Technical Report, National Bureau of Economic Research, http://www.nber.org/papers/w11805.pdf

Hilal M, 2007, “Temps d'accès aux équipements au sein des bassins de vie des bourgs et petites villes" Economie et Statistique $\mathbf{4 0 2} 41-56$

Hoxby C, 2003 The Economics of School Choice (Chicago University Press, Chicago, IL)

Hubert J-P, 2009, "Dans les grandes agglomerations, la mobilité quotidienne des habitants diminue, et elle augmente ailleurs" Insee Première number 1252 
Kenworthy J, Laube F, 1999, "Patterns of automobile dependence in cities: an international overview of key physical and economic dimensions with some implications for urban policy" Transportation Research 33(A) $691-732$

Larceneux A, 1997, "Mécanisme de décision et contexte local: l'offre de formation professionnelle initiale" Formation et Emploi 5957 - 70

Lemistre Ph, Magrini M-B, 2010, "Job qualification, distance between towns and geographic relocation for French youth" Urban Studies published online before print; doi:101177/ 0042098010382675

Manski C, Wise D, 1983 College Choice in America (Harvard University Press, Cambridge, MA)

Moller J, Waagepeterson R, 2005, "Statistical inference and simulation for spatial point processes" Journal of the American Statistical Association 100349 - 350

Müller S, Tscharaktschiew S, Haase K, 2008, "Travel-to-school mode choice modelling and patterns of school choice in urban areas" Journal of Transport Geography $16342-357$

Stair A, Rephann T, Heberling M, 2006, "Demand for public education: evidence from a rural school district" Economics of Education Review 25521 - 531 


\section{Appendix}

\begin{tabular}{|c|c|c|c|c|c|c|}
\hline & $\begin{array}{l}\text { Education } \\
\text { Stage }\end{array}$ & Age & \multicolumn{3}{|c|}{ Class and Diploma } & $\begin{array}{r}\text { School } \\
\text { Institution }\end{array}$ \\
\hline \multirow{6}{*}{ 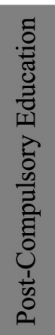 } & \multirow{3}{*}{$\begin{array}{l}\text { Higher Edu- } \\
\text { cation }\end{array}$} & \multirow{3}{*}{$\begin{array}{c}18 \\
\text { and } \\
\text { more }\end{array}$} & \multirow{2}{*}{\multicolumn{3}{|c|}{$\begin{array}{l}\text { Bac }+8 \text { years in higher educ.: PhD } \\
\text { Bac }+5 \text { years in higher educ.: Master }\end{array}$}} & \multirow{3}{*}{$\begin{array}{c}\text { "Lycée", } \\
\text { "Université", } \\
\text { "Grandes } \\
\text { Ecoles"... }\end{array}$} \\
\hline & & & & & & \\
\hline & & & \multicolumn{3}{|c|}{ Bac +2 years in higher educ.: BTS, Licence. } & \\
\hline & \multirow[t]{6}{*}{$\begin{array}{l}\text { Secondary } \\
\text { Education }\end{array}$} & \multirow{3}{*}{$\begin{array}{l}18 \\
17\end{array}$} & $\begin{array}{l}\text { "Secondary General } \\
\text { Education" (main- } \\
\text { stream) }\end{array}$ & \multicolumn{2}{|c|}{ "Secondary Vocational Education" } & \multirow{5}{*}{ "Lycée" } \\
\hline & & & & Term class for $\mathrm{Ba}$ & c Pro ${ }^{(2)}$ Diploma & \\
\hline & & & $\begin{array}{c}\text { Term Class for } \mathrm{Bac}^{(1)} \\
\text { Diploma }\end{array}$ & 1 st class for $\mathrm{Ba}$ & Pro Diploma & \\
\hline \multirow{5}{*}{ 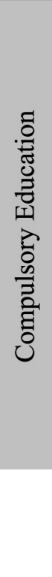 } & & 16 & 1st class & $\begin{array}{c}\text { 1st class for CAP } \\
\text { Diploma }\end{array}$ & $\begin{array}{c}\text { 1st class for BEP } \\
\text { Diploma }\end{array}$ & \\
\hline & & 15 & 2nd class & $\begin{array}{c}\text { 2nd class for CAP } \\
\text { diploma }\end{array}$ & $\begin{array}{l}\text { 2nd class for } \\
\text { BEP diploma }\end{array}$ & \\
\hline & & $\begin{array}{l}14 \\
13 \\
12 \\
11 \\
\end{array}$ & & $\begin{array}{l}\text { 3th class } \\
\text { 4th class } \\
\text { 5th class } \\
\text { 6th class }\end{array}$ & & "Collège" \\
\hline & $\begin{array}{l}\text { Primary Edu- } \\
\text { cation }\end{array}$ & $\begin{array}{c}10 \\
9 \\
8 \\
7 \\
6 \\
\end{array}$ & & & & \multirow[t]{2}{*}{ "Ecole" } \\
\hline & $\begin{array}{l}\text { Nursery Edu- } \\
\text { cation }\end{array}$ & $\begin{array}{l}5 \\
4 \\
3\end{array}$ & & & & \\
\hline
\end{tabular}

(1) Bac: "Baccalauréat" the secondary school-leaving exam required to attend higher education.

(2) Bac Pro: "Baccalauréat Professionnel" which designs the Baccalaureate obtained in vocational education; CAP is First Diploma and BEP is Second Diploma.

case 1

case 2

Figure A1. [In color online.] The National French Education System (table prepared by author). 
Table A1. Number of first year students for each case of training considered (2007) (source: The Government Board for Agriculture and Forestry of Midi-Pyrénées Region).

$\begin{array}{ll}\text { Town where school } & \begin{array}{l}\text { Percentage } \\ \text { is situated }\end{array} \\ \text { of boarders }\end{array}$

Percentage of students attending the closest school (for the training chosen)

\begin{tabular}{ll}
\hline weekday boarders & full \\
or day students & boarders
\end{tabular}

\begin{tabular}{|c|c|c|c|c|}
\hline BTSA ACSE & 1. Pamiers & 10 & 78 & 100 \\
\hline \multirow[t]{8}{*}{$\begin{array}{l}1 \text { st year } \\
\text { (case 1) }\end{array}$} & $\begin{array}{l}\text { 2. Villefranche de } \\
\text { Rouergue }\end{array}$ & 79 & 100 & 54 \\
\hline & 3. Toulouse & 26 & 35 & 37 \\
\hline & 4. Figeac & 0 & 58 & - \\
\hline & 5. Vic en Bigorre & 0 & 94 & - \\
\hline & 6. Albi & 15 & 45 & 40 \\
\hline & 7. Brens & 20 & 0 & 0 \\
\hline & 8. Verdalle & 0 & 38 & - \\
\hline & Total & 18 & 56 & 48 \\
\hline \multirow{9}{*}{$\begin{array}{l}\text { Bac Pro b } \\
1 \text { st class } \\
\text { (case } 2 \text { ) }\end{array}$} & 1. Rignac & 76 & 80 & 69 \\
\hline & 2. Montastruc & 22 & 83 & 62 \\
\hline & 3. Saint-Gaudens & 44 & 83 & 57 \\
\hline & 4. Masseube & 68 & 100 & 70 \\
\hline & 5. Cahors & 80 & 83 & 37 \\
\hline & 6. Brens & 63 & 75 & 22 \\
\hline & 7. Verdalle & 60 & 80 & 40 \\
\hline & 8. Caussade & 25 & 90 & 55 \\
\hline & Total & 51 & 85 & 47 \\
\hline
\end{tabular}

${ }^{a}$ BTSA ACSE: National Diploma in Agriculture: Analysis and Management of Farms.

${ }^{\mathrm{b}}$ Bac Pro: Professional Baccalaureate in Services for Rural Areas. 
Conditions of use. This article may be downloaded from the E\&P website for personal research by members of subscribing organisations. This PDF may not be placed on any website (or other online distribution system) without permission of the publisher. 